\title{
Mário de Andrade e Richard Wagner na aurora do modernismo paulista
}

\author{
EDUARDO TADAFUMI SATO ${ }^{I}$
}

\section{I}

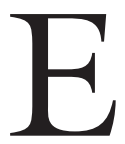
M ARTIGo publicado no jornal $A$ Gazeta em 31 de julho de 1919 e dedicado ao seu professor de piano Giuseppe Wancolle, Mário de Andrade apresenta uma leitura sobre a compreensão da expressão "música moderna”. Reconhecendo diferenças entre escolas nacionais de composição, ele ressalta a relevância para todas elas do compositor alemão Richard Wagner:

Sob a influência poderosa do gênio de Ricardo Wagner modificaram-se todas as escolas musicais; e desde então, como ninguém pudesse, embora afanosamente porfiando, imitá-lo, seguindo na pegada do possante reformador, cada qual tirou dele mais de um dos seus defeitos e qualidades - e todas essas diversas orientações se classificaram pomposamente de música moderna. A França, por influxo do autor do Parsifal viu nascer D'Indy, que deu origem à formação da Jeune École de efêmera duração. Desta, e consequentemente de Wagner, surgiram Fauré, Debussy, Ravel, Dukas, Rabaud. Massenet foi o último que explanou as delicadezas do meio-termo que eram as características da Escola Francesa; quanto a Saint Saens, é um homem de outras idades, um clássico que adormecendo nos tempos de Weber e de Gluck acordasse à balburdia do mundo hodierno para cantar o "Mon coeur s'ouvre a ta voix..." do segundo ato de Sansão a mais sublime melodia que explodiu dum coração humano.

Ainda sob a influência wagneriana o gênio de Verdi, transformando-se no que lhe era possível transformar suas tendências de melodista admirável, deu-nos Aida, Otelo e Falstaff, seus três maiores lavores e os três maiores orgulhos da Escola Italiana. Ainda Mascagni modificou-se, e foram aparecendo Boito, Franchetti, Perosi, Zandonai. Só Puccini... Mas não falemos em Puccini!

Houve quem chegasse a assinar a Wagner a paternidade da Escola Russa. Há um exagero manifesto nessa afirmativa, embora a ele se devam as modificações poderosas por que passaram os artistas russos. A mais moça de todas as escolas musicais é talvez a que ainda se poderá afirmar que existe; mas em Scriabin, por exemplo, nada ou quase nada reside do fundo popular, da dolente nostalgia que dão à Escola Eslava a auréola de ser a mais amarga e mais humana. 
Apenas a ânsia, já imperialista do autor de Tristão e Isolda - que desejara, antes de mais nada, uma escola genuinamente alemã, dominadora de todas as outras - não se realizou. Poder-se-á mesmo dizer que na Alemanha o seu influxo foi antes dispersivo e iconoclasta que gerador e bom. Da esperança orgulhosa da escalada, dos céus é que nasceram as babéis e as lendas dos Titãs: modernamente, as duas orgulhosas esperanças de instauração de uma música alemã dominadora e duma hegemonia militar germânica sobre todas as gentes e civilizações, ao passo que restaurava as forças adversárias, produzia, aquela, o aniquilamento em que jaz a música alemã, só tendo produzido de grandes Brahms e Strauss, esta, o aniquilamento duma raça que pudera ser grande, mas que está a morrer devorada por suas próprias impulsões desvairadas. (Andrade, 1918a, p.1)

Mário de Andrade, recém-formado no Conservatório Dramático e Musical, onde lecionava história da música e piano, escrevia para jornais e revistas sobre música e sobre os espetáculos realizados na cidade de São Paulo. As leituras que realizava para preparo das suas aulas contribuíam para que ele acumulasse um conhecimento musical pouco habitual para aquele momento (Toni, 2013). Ele compreendia a importância das ideias musicais de Richard Wagner e a forma como essas foram adaptadas por diferentes tradições musicais, mas cujos repertórios eram pouco executados em São Paulo (Lago, 2010). Mário entende que nos compositores franceses, a influência de Wagner se dá a partir de Vincent D'Indy e da Jeune École, do mesmo modo que a ópera italiana se transforma na obra tardia de Giuseppe Verdi devido a essa mesma influência. Apesar disso, aponta também a existência de exceções a essas propostas, como Camille Saint Saens e Giacomo Puccini, respectivamente. Ele critica a ideia de um protagonismo wagneriano na escola russa, ainda que reconheça a importância de sua influência. Em relação à escola alemã, Mário aponta o fracasso do projeto de Wagner de erigir uma hegemonia germânica na música, relacionando-o com a derrota militar na recém-encerrada Primeira Guerra Mundial. Preocupado com a realização de um diagnóstico sobre o estado do desenvolvimento musical após o conflito, Mário apresenta essa situação de dispersão, na qual a todas essas diferentes propostas se pode atribuir o adjetivo de moderno.

Em artigo do dia seguinte que recebe o mesmo título, "Para Giuseppe Wancolle", Andrade (1918b) retoma o tema da música moderna a partir de outra perspectiva, ao apresentar o relato do compositor francês Camille Saint-Saens sobre a peça musical chamada "Cavaleiro Verde" realizada por clube boêmio ligado ao desenvolvimento do drama lírico, localizado na Califórnia. Assim procede com o intuito de demonstrar que não é pelo "desejo de rebuscas esquisitas e de originalidade" (ibidem) que se funda a música moderna. Utilizando-se de uma ideia remanescente romântica que é a figura do "gênio", Mário afirma que esses seriam originais como consequência de fatores da sua personalidade e não devido a formulações teóricas e estéticas singulares. Apresenta, assim, o caso de Claude Debussy: 
Se Debussy soube ser original e fantasista é porque não foram estes os seus desígnios, antes qualidades inatas no seu estranho temperamento artístico. [...] Debussy, libertado de todas as regras que lhe impediam o desenvolvimento das largas alas, soube ser verdadeiramente grande, legando aos musicistas uma fortuna de joias inconfundíveis. (Ibidem)

O compositor francês é entendido como exemplo desse tipo de gênio por transportar traços de sua personalidade à sua obra de maneira original. Essa concepção encontra eco na comparação realizada com Wagner, e está ligada à percepção de que ambos os compositores não formarão escolas. Baseando-se em livro de Octave Sére, Mário afirma que, mesmo que a música de Debussy tenha esgotado "nas suas obras os recursos que lhe auferiam os seus processos harmônicos", não encontrará uma continuidade por não representar os “sentimentos fortes que se originam da vida" (ibidem), sendo incapaz de expressar adequadamente as circunstâncias da vida moderna, com o sistema omnitônico. Como se Mário adiantasse uma intuição sobre a necessidade de um papel do primitivismo para a expressão moderna, não vê desenvolvimentos à vista a partir dos desdobramentos expressivos do compositor francês.

Nesses breves textos, os argumentos que Mário de Andrade apresenta sobre os desenvolvimentos da música moderna são ainda incipientes. São poucos os termos técnicos ou formais utilizados para explicar as mudanças estéticas, o que não significa nem que o escritor não dominasse tais conteúdos, nem que se posicionasse a favor de uma ausência de rigor. Aproveitava o espaço cedido nas páginas do jornal para divulgar suas ideias sobre a música, nos momentos em que não exercia a função mais pragmática de escrever críticas musicais logo após a realização de recitais e concertos. Poucos anos depois, dotado de maior reconhecimento, e de mais espaço para desenvolver suas ideias, apresenta conferência na Vila Kyrial, círculo intelectual ao qual começa a adentrar no último ano década de 1910, chamada "Debussy e o impressionismo". Além de apresentar um paralelo com as artes plásticas e de buscar mostrar o que significava um impressionismo na música, Mário dedica parte do seu discurso para estabelecer e ampliar o seu vínculo com Richard Wagner e expor sua compreensão sobre o papel do compositor alemão na história da música. Ao se perguntar sobre quais seriam as influências de Debussy, responde "nenhuma francesa ou de música executada na França até então", e reconhece a antecedência wagneriana mesmo que como "um esforço de reação", ao qual conclui em palavras diretas:

Debussy não existiria se não existisse Wagner. A "politonalidade" do autor dos Noturnos não é uma flor de raro perfume, nascida por geração espontânea: jamais abrolharia sem o cromatismo fecundo do Tristão. (Andrade, 1993, p.103)

Finaliza sua apresentação da importância do compositor alemão realizando um paralelo com a história política:

A reforma wagneriana é uma espécie de revolução francesa musical. 1865, 
data do Tristão e Isolda é o 89 da história da música. O seu influxo foi unânime, mundial; e talvez mesmo mais eficaz naqueles que contra ele reagiram. (Ibidem)

Ao mesmo tempo, todavia, Mário expõe o esgotamento da harmonia tonal a partir do cromatismo como recurso levado ao limite por Wagner, que consegue retirar o limite de expressividade a partir da ideia de leitmotif. Conclui, concordando com a famosa afirmação de Debussy: "Wagner foi um esplêndido pôr-do-sol que se tomou por uma aurora". Essa fórmula é aceita para Mário como aplicável a ambos os compositores: Wagner explora a limites extremos as melhores realizações da sua proposta estética; Debussy pela "difaneidade e flexibilidade dos exemplos que apresentou". Para o poeta, porém, não fazer escola não significa não ter influência, já que ambos podem ser entendidos como fundamentais para os futuros desenvolvimentos harmônicos na música.

As leituras que Mário de Andrade apresenta acerca de Richard Wagner ressaltam a existência de um projeto estético bem acabado e realizado, porém sem uma continuidade possível a não ser a partir de oposições e críticas, entendimento que é semelhante ao modo como caracteriza a poesia de Olavo Bilac no Prefácio interessantíssimo:

Explica-se historicamente o seu defeito: Tarde é um apogeu. As decadências vêm depois dos apogeus. O apogeu já é decadência, porque não pode conter em si um progresso, uma evolução ascensional. Bilac apresenta uma fase destrutiva da poesia; porque toda perfeição em arte significa destruição. (Andrade, 2013, p.70-1)

Se essa imagem da Tarde se mantém utilizável para ambas as leituras, podemos inferir que um projeto estético de Mário de Andrade não segue cegamente as ideias sobre a música do autor de Parsifal, mas medita sobre elas, reconhecendo os seus limites e aproveitando o necessário como lição.

\section{II}

Nos trechos acima transcritos, Mário de Andrade apresenta os impasses da música moderna, representados pelas composições de Richard Wagner e Claude Debussy retirados principalmente dos livros de história de música que lia e com os quais se atualizava. Há poucas menções a ambos compositores nas críticas musicais que escreve a partir do que assiste nos palcos na década de 1910. Com a presença incipiente do compositor francês nos recitais de pianos sobre os quais escrevia, quase não o menciona, e quando o faz o foco está no intérprete (Andrade, 1918c). Em relação a Wagner a situação é de ainda maior distanciamento: com a Primeira Guerra, as companhias de ópera que vinham ao Brasil - que tinham como base teatros, elencos e músicos italianos e franceses - não apresentam o repertório alemão, do qual Wagner é o principal expoente. ${ }^{1}$ Mário, que escreve para $A$ Gazeta sobre todas as récitas da temporada lírica oficial de 1918 e de metade da temporada realizada em 1919, não trata do compositor alemão, pois não presencia a apresentação de nenhuma de suas obras. É somente 
na temporada de 1920 que as obras de Wagner retornam aos palcos paulistas, ainda que em suas versões traduzidas para o italiano, prática comum no período (Cerquera, 1954).

A apreciação musical baseada nas turnês de grupos europeus e dependente dos empreendimentos de empresários que organizavam as temporadas líricas era o único modo pelo qual se podia ter contanto com o repertório europeu canônico, desde o final do século XIX, na cidade de São Paulo. Sem a existência de grupos orquestrais organizados ou de um ensino de música sistematizado, restava a presença de grupos itinerantes para ocupar os palcos da cidade. Esse modelo tem seu ápice a partir da inauguração do Teatro Municipal de São Paulo em 1911. Fruto do crescimento econômico ligado à produção cafeeira, o Teatro erguido pelo escritório de Ramos de Azevedo pode ser entendido como marco civilizatório para a cidade. Às margens do vale do Anhangabaú, projeta-se como símbolo da expansão da fronteira da cidade para além dos seus limites naturais - progresso técnico que duas décadas antes já erguera o Viaduto do Chá. Um teatro lírico é compreendido como índice necessário na medida da emancipação e progresso de uma cidade. A literatura sobre o tema trata da influência do Ópera de Paris para as casas de ópera inauguradas entre o último quarto do século XIX e o primeiro do XX. Há, porém, uma relevância simultânea de dois projetos: além do edifício de Charles Garnier, o Teatro de Festivais de Bayreuth. São duas propostas divergentes que encontram uma síntese nos teatros do período, especialmente naqueles da América do Sul.

Se, por um lado, a proposta do Ópera Garnier serve como grande inspiração arquitetônica para a construção de muitos teatros ao redor do mundo, o Teatro de Bayreuth exerce um outro tipo de influência, relacionada à concepção wagneriana de obra de arte total (Gesamtkunstwerk). A transformação presente nessa proposta advém de uma modificação no entendimento da obra de arte que passa a extrapolar os limites que até então lhe eram atribuídos: tudo se passa como se a própria estrutura dos teatros não pudesse comportar esse novo projeto estético. A solução de Wagner se materializa na construção no Teatro de Bayreuth, em parceria com o arquiteto Gottfried Semper, inaugurado em 1876. O propósito de seu desenho arquitetônico era direcionar todos os olhares para o que ocorria no palco. Se o teatro de Paris é pungente em ornamentos e na demonstração das hierarquias sociais, o que acontece em Bayreuth é o oposto: quase não há decoração e o auditório é organizado para que todos os membros da audiência possam ter uma visão clara e sem obstáculos do palco. Ou seja, se no projeto parisiense há uma dispersão da ideia de palco, que passa a englobar também a sociedade que circula pelos espaços do teatro, o projeto alemão radicaliza o oposto, convergindo todos os olhares em um único ponto e gerando um fenômeno que poderíamos entender como a sacralização do palco. A ideia de uma melodia infinita, cuja produção está escondida pela estrutura do teatro, gera esse efeito mágico que concentra a atenção dos espectadores. 
Essa mudança no foco da experiência teatral exige a criação de um novo comportamento no público, capaz de compreender essa nova linguagem e seus códigos. Para tanto, faz-se necessária uma reeducação dos sentidos e um reaprendizado das convenções em jogo. É nessa lacuna que a crítica musical passa a ter papel determinante. Ela formula as experiências vividas no teatro e as traduz, aproximando dessa maneira público e obra de arte.

Mário de Andrade, versado na linguagem musical, podia realizar essa tarefa de maneira profícua. Nesse período em que escrevia para $A$ Gazeta, sua crítica não seguia um padrão único: fala sobre a linguagem musical, sobre os intérpretes, sobre o enredo, sobre o público e sobre as interações entre essas esferas. Pode-se dizer que havia nos seus escritos um caráter didático, pois ajudava o leitor a elaborar a experiência vivida como espectador. Essa abordagem se contrapõe a uma crítica musical que se poderia chamar de doutrinária, que impõe padrões de gosto, estabelecendo valores e hierarquias. Essa fluidez da crítica do Mário da década de 1910, que experimenta com esse gênero jornalístico, leva-o em alguns casos a uma imersão no lugar da plateia. Fluente no vocabulário religioso, visto que a Igreja fora fundamental nos seus anos formativos, compreende e expressa essa vivência inspirado no ritual eclesiástico. É como se Mário aceitasse e vivesse o palco como um espaço sagrado, em paralelo à proposta wagneriana.

Em seu primeiro artigo no jornal $A$ Gazeta publicado em 9 de julho de 1918, Mário relata as apresentações do pianista polonês Artur Rubinstein:

Vimos também, cheios de um prazer respeitoso, depor o nosso grão de incenso na ara do semideus.

Nenhum outro anseio nos exalta. Os antigos, humildes e grandes, não desdenharam nunca de levar a oblata das guirlandas votivas para ornar os pedestais dos seus numes. A nossa guirlanda de louvores entressacrar-se-á às outras muitas que Rubinstein tem colhido nesta sua viagem pelas capitais sul-americanas.

Mas o grande pianista parece desdenhar dos louvores humanos... Quando, sentado ao piano, ele traduz e evoca o misterioso sentir dos mestres, os seus olhos se cerram muitas vezes e a sua cabeça inclina-se para trás... Sem dúvida, a sua alma sutil e prodigiosa, eleva-se para a região onde demoram os espíritos dos grandes músicos e vai buscar, daqueles que traduziram em sons as comoções da sua vida, o sorriso do aplauso e a lágrima da gratidão. (Andrade, 1918c)

O trecho pouco diz sobre os recitais ocorridos nos dias anteriores, fugindo das convenções das colunas teatrais, mas oferece a ideia da experiência musical como ritual religioso. Não apresenta termos técnicos associados à música ou à execução do pianista, mas traz um vocabulário com palavras ligadas à religião, como "ara", "oblata" e "numes". Essa maneira de conceber a crítica, privilegiando suas impressões em detrimento de uma objetividade na descrição, aparece como escolha do crítico e não como uma limitação técnica, de modo que é possível atribuir uma intenção criadora em um ofício em que isso não era um requisito. 
Richard Wagner radicaliza a proposta de uma aproximação entre religião e ópera nas suas últimas obras. Parsifal, de 1882, tem como subtítulo "Ein Bühnenweihfestspiel", uma peça festiva de consagração do teatro. Seu tema envolve a busca pelo Santo Graal e a figura do herói Parsifal. Debussy, contrário a Wagner, identifica-o com o antagonista do enredo, que buscava determinadamente a sua autorrealização.

Não é minha intenção discutir aqui a genialidade de Wagner. Sem dúvida, sua força foi dinâmica. Mas seus efeitos foram maiores devido à maneira pela qual foram preparados por sagazes mágicos cuja astúcia não tem limites [...]. Talvez seja o lamento extraordinariamente angustiado em sua música o responsável pela profunda impressão que Wagner deixa no espírito contemporâneo; ele despertou o anseio secreto pelo que é criminal, em algumas das mais famosas mentes de nosso tempo. Para concluir, as obras de Wagner sugerem uma imagem das mais impactantes: Bach é o Santo Graal, Wagner é Klingsor, que quer destruir o Graal e tomar seu lugar. Bach reina [...] Wagner desaparece. Uma escuridão medonha, negra como a fuligem. (Debussy 1903, apud Abbate; Parker, 2015, p.490)

Mário de Andrade concorda em parte com Debussy. Como já vimos, ele condena a posição imperialista assumida por Wagner, mas ao mesmo tempo cede aos encantos da sua proposta artística ao se aproximar de um estado de transe religioso na sua relação com a música.

\section{III}

A entrada de Mário de Andrade nos meios literários, artísticos e intelectuais é feita de maneira gradual, colocando-o pouco a pouco nos holofotes da Pauliceia. O ano 1917 é decisivo para esse processo: enfrenta a morte do pai, o que lhe atribui alguma maior responsabilidade dentro da família; gradua-se no Conservatório Dramático e Musical, onde é "descoberto" por Oswald de Andrade e outros jornalistas que se impressionam com a resposta à conferência de Eloy Chaves que profere; lança o seu primeiro livro de poesias, Há uma gota de sangue em cada poema sob o pseudônimo Mario Sobral; passa da posição de espectador passivo a uma participação mais ativa nas exposições de arte: adquire sua primeira tela, uma paisagem de Torquato Bassi, e faz-se notar na célebre exposição de Anita Malfatti. Essas iniciativas vão tornando-o cada vez mais conhecido na cidade e permitem sua progressiva saída do anonimato. Passa a escrever para diferentes periódicos e aumenta o leque de assuntos nos quais se arrisca. Até 1921 , já terá tratado de música, literatura e política em críticas, crônicas, ensaios e conferências para periódicos como A Gazeta, Correio Paulistano, Jornal do Comércio, Ilustração Brasileira e Correio Musical Brasileiro. Esse movimento contínuo, porém, muda de ritmo e é acelerado em 1921, como se acompanhasse os movimentos da cidade nas vésperas do Centenário da Independência. Um dos estopins da mudança é o texto que publica Oswald de Andrade no Jornal do Comércio, em 27 de maio de 1921, no qual introduz o seu "poeta futurista". 
Texto bastante explorado pela crítica literária, ao menos desde a publicação do livro de Mário da Silva Brito, tem uma grande repercussão na vida do professor de piano que vai posteriormente recusar o rótulo de futurista para afirmar uma necessária liberdade de criação. Nesse texto, porém, há ainda outras referências, de caráter musical, que foram pouco destacadas e que proporcionam outra leitura possível para a situação.

É longo como um círio e evoca para as minhas meditações babilônicas um cálice do Graal suspenso aos lábios ávidos da "girl” babilônica que é esta cidade de mil portas.

Chama-se... não posso thes contar o nome simples. Proibiu-me o casto, o bom, o tímido. Contar-lhe-ei a figura e a arte. (Andrade, 1921 in Brito, 1964, p.228)

Oswald não nomeia o poeta a quem homenageia, mas apresenta ainda de maneira enigmática sua relação com a cidade e a figura do Graal. Não anuncia o seu nome, tema com o qual brinca durante o texto, mas prossegue apresentando suas obras, enunciando o seu trabalho, além de publicar uma poesia sua, "Tu", de Pauliceia desvairada, livro ainda inédito.

Vejo-o no pavor e na coragem, ambos extremados, dos conduzidos às forças sensacionais. Pobre delicioso... Ia lançar-lhe o nome simples.

Esse lívido e longo Parsifal bem-educado é conhecido pelo seu saber crítico. Publica-se no armário bem fornido da "Revista do Brasil", escreve no "Jornal de Debates", faz parte relevante de "Papel e Tinta", leciona com rara honestidade de erudição no nosso Conservatório. Mas o que adoro nele, na sua aristocrática alma íntima, é o artista invejável, o artista imenso da nossa cidade. (Ibidem)

O Graal se desdobra em nova referência: Parsifal, personagem mitológico, mais conhecido por protagonizar o enredo da última ópera de Richard Wagner. A maneira como o personagem é apresentado pelo compositor traz semelhanças com o modo como Oswald constrói seu artigo. No libretto, Parsifal é o herói que salva a irmandade do Santo Graal. Ele primeiro aparece em cena como um jovem que atira uma flecha e mata um cisne na floresta sagrada e ao ser indagado por Gurnemanz, o cavaleiro mais velho da irmandade do Graal, sobre as motivações para o ato e sobre sua identidade, revela não saber tais respostas. A única coisa que ele sabe é o nome de sua mãe, Herzeleide (sofrimento do coração), que vivia junto a ela na floresta e que ele próprio construíra o arco que usou para caçar o cisne. Gurnemanz questiona porque ele não usa armas melhores já que aparenta ser bem-nascido (hochgeboren). A ingenuidade de Parsifal ressoa para os cavaleiros do Graal como a profecia de que somente o "puro inocente" (Der reine Tor) poderia curar o rei Anfortas da ferida realizada por Klingsor - antigo candidato a cavaleiro do Graal, que não sendo aceito busca vingança - com a Lança Santa. Assim, é levado à presença do objeto sagrado, mas permanece impassível sem demonstrar compaixão ou afinidade, sendo expulso do castelo 
pelo frustrado Gurnemanz. É somente quando ouve seu nome pronunciado pela bruxa Kundry, que tenta seduzi-lo transformada em uma bela mulher, que voltam à memória seu passado e as lembranças de sua mãe e que afloram sentimentos que estavam até então adormecidos e Parsifal recupera a sua realeza. O beijo da mulher o leva a um estado de transe em que rememora as lembranças sobre o sofrimento do rei, a magia de Klingsor sobre Kundry e sua missão de salvar a irmandade do Graal. ${ }^{2}$

Oswald, que provavelmente teve contato com a ópera apresentada poucos meses antes da publicação do texto, durante a temporada lírica de 1920, relê Wagner: o "puro inocente" torna-se o "pobre delicioso"; a aparência de bem-nascido torna-se a "aristocrática alma íntima". Como se baseado numa análise estruturalista, ele adapta o mito: Parsifal ao ouvir seu nome lembra-se da sua missão; Mário não tem o seu nome anunciado, ação talvez não necessária, mas é lançado ao debate público, como se fosse um cavaleiro a defender o futurismo.

Mário posteriormente responde a esse chamado em algumas ocasiões, sempre questionando o rótulo de futurista. O primeiro deles é no próprio Jornal do Comércio em 6 de junho de 1921. "O pobre anda pelas ruas crucificado numa interrogação!...”. Essa é a imagem que Mário evoca para questionar o alinhamento proposto por seu colega à escola estética de Marinetti. Apesar de reconhecer possíveis semelhanças entre a proposta da Pauliceia desvairada e do futurismo, como apontadas na provocação de Oswald, Mário defende um não alinhamento com nenhuma escola estética, mas admite sua poesia como obra de circunstância, voltada para o presente, mesmo que seja escrito apenas para sua própria intimidade. O recurso lançado por Mário é se afastar do "poeta futurista", apesar da sua paridade, tratando-o na terceira pessoa, como se fosse um personagem fictício criado por Oswald de Andrade. Tudo se passa como se Mário se enxergasse na figura criada por Oswald, mas não pudesse se assumir totalmente desse modo, fazendo um diagnóstico de si próprio como distante de si mesmo:

O poeta de "Pauliceia Desvairada" não é um futurista e, principalmente jamais se preocupou de "fazer futurismo". Ele consente que o chamem de extravagante, original, atual, maluco, do "domínio da patologia" (frase já estereotipada entre os zoilos) mas não admite que o prendam à estrebaria malcheirosa de qualquer escola. (Andrade, 1964, p.238)

É no "Prefácio interessantíssimo", da Pauliceia desvairada, que vai retomar o assunto na primeira pessoa, falando de si próprio e esclarecendo o seu propósito:

Não sou futurista (de Marinetti). Disse e repito-o. Tenho pontos de contato com o futurismo. Oswald de Andrade, chamando-me de futurista, errou. A culpa é minha. Sabia da existência do artigo e deixei que saísse. Tal foi o escândalo, que desejei a morte do mundo. Era vaidoso. Quis sair da obscuridade. Hoje tenho orgulho. Não me pesaria reentrar na obscuridade. Pensei que se discutiram minhas ideias (que nem são minhas): discutiram 
minhas intenções. Já agora não me calo. Tanto ridicularizaram meu silêncio como esta grita. Andarei a vida de braços no ar, como indiferente de Watteau. (Andrade, 2013, p.62)

Durante a Semana de Arte Moderna também escreve em coluna para o jornal A Gazeta, em diálogo diário com Voltolino, acerca de questões estéticas dentre as quais a defesa do termo "modernismo" em detrimento a "futurismo". Essa série de artigos, assim como a dos "Mestres do Passado", dedicada a poetas parnasianos, publicadas no Jornal do Comércio como sequência ao debate entre Oswald e Mário, mostra um autor que toma posições utilizando-se do próprio nome, carregando as bandeiras e os rótulos que atribui a si próprio, não mais escondido em pseudônimos como fazia até $1920 .^{3}$

Voltando ao retrato do "poeta futurista", vemos que Mário refuta o rótulo, porém outra comparação vai agradar ao professor de música. Parsifal é figura com a qual Mário exibe afinidade e semelhança. Nesse sentido, não é uma recusa total ao artigo e ao personagem de Oswald, mas uma aceitação que é até transformada em objeto criativo: escreve poesia, não localizada e que não entrou na Pauliceia desvairada, que se inicia como: "Louco entre os loucos, eu sou o Parsifal!". "Essa identificação autoproclamada está presente na correspondência com Manuel Bandeira: em carta de 4 de agosto de 1922, assim se despede Bandeira do seu interlocutor: "Recebeu uma maçante carta minha? Escreva-me, Parsifal!” (M. de Andrade, 2001, p.68); e quando recebe o seu exemplar da Pauliceia, responde em 3 de outubro do mesmo ano ao colega paulista:

Vou falar com franqueza, já que você m’a pede, dos seus poemas tão belos e tão estranhos. Quando os ouvi, lidos por você, senti-me arrastado pelo aluvião lírico do Desvairismo. O "Oratório”, o "Noturno" e outro poema, que você suprimiu ("Louco entre os loucos, eu sou o Parsifal!"), deixaram em mim a ressonância de inumeráveis harmônicos. Tinha realmente, ânsia de lê-los. (Ibidem, p.69)

\section{IV}

Mário não se identifica com Richard Wagner, como se este fosse uma lição aprendida de proposta estética que se encerra em si mesma, mas se identifica com Parsifal, na narrativa que acima está transcrita. Uma leitura direta do próprio autor para essa questão - a poesia que fazia referência direta ao personagem da ópera - hoje está perdida, esvaída assim como a voz que leu e impactou Manuel Bandeira, o único que registrou essa existência. De maneira indireta, a história do teatro de ópera serve como cenário para o desenrolar dessa narrativa: a mudança na paisagem da cidade e a dinamização da vida, tiveram como um de seus protagonistas o Teatro Municipal de São Paulo, síntese entre propostas estéticas que vão além do palco. Arquitetura que marca a paisagem e inspira. Mário ilustra essa passagem: da igreja para o teatro, da vida privada ao julgamento público. Mário medita sobre a lição do mestre alemão: em relação às suas posições políticas, a crítica é direta; sobre seu projeto estético, considera 
esgotado, mas valioso; e se identifica com um personagem, que junto a outros, como o Arlequim, compõe sua múltipla e inesgotável personalidade.

\section{Notas}

1 A exceção é a $9^{a}$ Sinfonia de Ludwig van Beethoven, que tem sua estreia no Brasil em 1918. Uma provável leitura para tal fato é de que Beethoven não era entendido pela sua nacionalidade, mas pela sua genialidade universal.

2 Esse resumo está baseado na sinopse do Metropolitan Opera de Nova York, disponível em: <http://www.metopera.org/Discover/Synposes-Archive/Parsifal/> e também no libreto da ópera e sua tradução para o inglês, disponível em: <http://www.rwagner. net/libretti/parsifal/e-t-pars.html>. Acesso em: 17 nov. 2015.

3 Alguns exemplos de nomes com que assina no período são: "Mário Sobral” em Há uma gota de sangue em cada poema, "Mário de Morais Andrade" e "M.A." em A Gazeta, "M. de Moraes Andrade" e "Dom José" em A Cigarra, "Ivan" em Ilustração Brasileira, "Mario Raul", "Pedro de Alencar", "Antonio Cabral”, "Sacy Perere", "Mário de Andrade" e "Morais Andrade" em Papel e Tinta.

4 É interessante notar que as referências a Wagner e Parsifal não terminam nesse momento da obra de Mário de Andrade. São temas debatidos ao longo de sua carreira, seja como musicólogo, escritor ou crítico. Para citar alguns, respectivamente: o ensaio Romantismo musical, a influência germânica no Amar, verbo instransitivo e o artigo "Parsifal", de 1943, em que traduz o significado do nome do personagem principal como o "louco inocente".

\section{Referências}

ABBATE, C.; PARKER, R. Uma história da ópera. São Paulo: Cia. das Letras, 2015.

ANDRADE, M. de. Para Giuseppe Wancolle. A Gazeta, São Paulo, 31.7.1918a.

Para Giuseppe Wancolle. A Gazeta, São Paulo, 1.8.1918b.

Rubinstein. A Gazeta, São Paulo, 9.9.1918c.

Futurista!! In: BRITO, M. da S. História do Modernismo Brasileiro: I. Antecedentes da Semana de Arte Moderna. Rio de Janeiro: Civilização Brasileira, 1964. p.234-8.

. Debussy e o impressionismo. Revista Arca, Porto Alegre, n.1, 1993.

. Correspondência Mário de Andrade é Manuel Bandeira. Organização, intro-

dução e notas Marcos Antônio de Moraes. 2.ed. São Paulo: Edusp; IEB, 2001.

Poesias completas. Rio de Janeiro: Nova Fronteira, 2013. v.1.

ANDRADE, O. de. Meu poeta futurista. Jornal do Comércio (ed. de São Paulo), 27.5.1921.

BRITO, M. da S. História do Modernismo Brasileiro: I. Antecedentes da Semana de Arte Moderna. Rio de Janeiro: Civilização Brasileira, 1964.

CERQUERA, P. Um século de ópera em São Paulo. São Paulo: s. n., 1954.

DEBUSSY, C. Gil Blas. s. 1.: s. n., 1903. 
LAGO, M. A. C. do. O círculo Veloso-Guerra e Darius Milhand no Brasil: Modernismo musical no Rio de Janeiro antes da Semana. Rio de Janeiro: Reler, 2010.

SATO, E. T. Mário de Andrade n'A Gazeta (1918-1919): um "plumitivo incipiente"?. 2016. Dissertação (Mestrado em Estudos Brasileiros) - Instituto de Estudos Brasileiros, Universidade de São Paulo. São Paulo, 2016.

TONI, F. C. Revistas musicais estrangeiras e compositores modernos na biblioteca de Mário de Andrade. Remate de Males, Campinas, v.33, n.1-2, p.225-44, 2013.

RESUMO - O início da carreira intelectual de Mário de Andrade é marcado por aproximações com o compositor alemão Richard Wagner de diversas maneiras. No presente artigo, apresento três modos pelos quais os autores se encontram: o primeiro é a leitura que Mário faz da obra de Wagner; o segundo, parte da importância do compositor e seu projeto estético na história da música; o terceiro traz o caso da apresentação realizada por Oswald de Andrade que utiliza termos da ópera Parsifal. A partir desses, propõe-se uma leitura do pensamento musical de Mário de Andrade que pode ser utilizada de amparo para a compreensão do seu pensamento estético.

PaLAVRAS-CHAVE: Mário de Andrade, Richard Wagner, Modernismo, Música, Crítica.

ABSTRACT - The beginning of Mário de Andrade's intellectual career is marked by his many approximations to the German composer Richard Wagner. In this article, I would like to present three excerpts that show how these two authors meet: the first is Mário's reading of Wagner's work; the second concerns the importance of this composer and his aesthetic project in the history of music; the third relays the case of a presentation by Oswald de Andrade that makes a comparison to the opera Parsifal. From these excerpts, I would like to propose a reading of Mário de Andrade's musical thought that may be used as a basis to understand his aesthetic thinking.

KEYWORDS: Mário de Andrade, Richard Wagner, Modernism, Music, Criticism.

Eduardo Tadafumi Sato é mestre em Estudos Brasileiros pelo Instituto de Estudos Brasileiros da Universidade de São Paulo. @ - eduardo.sato@usp.br

Recebido em 5.7.2017 e aceito em 27.7.2017.

${ }^{\mathrm{I}}$ Instituto de Estudos Brasileiros, Universidade de São Paulo, São Paulo, São Paulo, Brasil. 